\title{
Depression of peripheral chemosensitivity by a dopaminergic mechanism in patients with obstructive sleep apnoea syndrome
}

\author{
S. Osanai, Y. Akiba, S. Fujiuchi, H. Nakano, H. Matsumoto, Y. Ohsaki, K. Kikuchi
}

\begin{abstract}
Depression of peripheral chemosensitivity by a dopaminergic mechanism in patients with obstructive sleep apnoea syndrome. S. Osanai, Y. Akiba, S. Fujiuchi, H. Nakano, H. Matsumoto, Y. Ohsaki, K. Kikuchi. (C)ERS Journals Ltd 1999.

ABSTRACT: In the present study, respiratory drives to chemical stimuli and peripheral chemosensitivity were evaluated in patients with obstructive sleep apnoea (OSAS). The effects of oral administration of domperidone, a selective dopamine $D_{2^{-}}$ receptor antagonist, were also examined, to study the respiratory effects of endogenous dopamine on peripheral chemoreceptors.

Sixteen patients with OSAS and nine normal control subjects were studied. Respiratory responses to hypercapnia and hypoxia were measured using the rebreathing method and isocapnic progressive hypoxia method, respectively. The hypoxic withdrawal test, which measures the decrease in ventilation caused by two breaths of $100 \% \mathrm{O}_{2}$ under mild hypercapnic hypoxic conditions (end-tidal oxygen and carbon dioxide tensions $\approx 8.0 \mathrm{kPa}$ and $5.3-6.7 \mathrm{kPa}$, respectively), was used to evaluate peripheral chemosensitivity.

In the patients with OSAS, ventilatory responses to hypercapnia and hypoxia were significantly decreased compared with those of control subjects. Hypoxic withdrawal tests showed that peripheral chemosensitivity was significantly lower in patients with OSAS than in normal subjects. Hypercapnic ventilatory response and peripheral chemosensitivity were enhanced by administration of domperidone in the patients with OSAS, although no changes in either of these were observed in the control subjects. The hypoxic ventilatory response and peripheral chemosensitivity in the patients with OSAS were each significantly correlated with severity of hypoxia during sleep.

These findings suggest that peripheral chemosensitivity in patients with obstructive sleep apnoea syndrome may be decreased as a result of abnormality in dopaminergic mechanisms and that the reduced chemosensitivity observed in patients with obstructive sleep apnoea syndrome may affect the severity of hypoxia during sleep. Eur Respir J 1999; 13: 418-423.
\end{abstract}

First Dept of Internal Medicine, Asahikawa Medical College, Asahikawa, Japan.

Correspondence: S. Osanai

First Dept of Internal Medicine

Asahikawa Medical College

Nishikagura 4-5-3

Asahikawa 078

Japan

Fax: 81166682449

Keywords: Control of breathing domperidone

dopamine receptor

hypoxic withdrawal response

peripheral chemoreceptor

Received: August 51996

Accepted after revision September 241998

Obstructive sleep apnoea syndrome (OSAS) is characterized by frequent episodes of upper airway closure during sleep [1]. This airway collapse is due to both a narrow upper airway and a decrease in muscle tone during sleep [2]. It has also been suggested that the critical trigger of apnoea might be instability of breathing during sleep [3] and that the duration of apnoea is influenced by individual respiratory drive $[4,5]$. The ventilatory response in patients with OSAS has, therefore, been studied in detail over the last two decades. However, the role of peripheral chemoreception in this syndrome has not been adequately evaluated.

In the present study, the ventilatory response to chemical stimuli and peripheral chemosensitivity was measured in patients with OSAS using the hypoxic withdrawal test [6-8]. The respiratory effect of endogenous dopamine, a major neurotransmitter $[9,10]$ which might inhibit peripheral chemoreceptors $[11,12]$, was also assessed by administration of domperidone, a dopamine antagonist [13].

\section{Materials and methods}

\section{Study groups}

The present experiments were performed with 16 patients with OSAS and nine control subjects (table 1). The diagnosis of OSAS had been reached by standard full-
Table 1. - Characteristics of subjects

\begin{tabular}{lcc}
\hline & Control subjects & Patients with OSAS \\
\hline Sex M/F & $7 / 2$ & $14 / 2$ \\
Age yrs & $43.7 \pm 4.7$ & $46.6 \pm 3.1$ \\
& $(24-62)$ & $(24-65)$ \\
BMI kg.m ${ }^{-2}$ & $27.2 \pm 2.4$ & $27.8 \pm 1.4$ \\
& $(20.9-38.5)$ & $(18.9-42.8)$ \\
VC \% pred & $100.1 \pm 3.9$ & $105.0 \pm 2.6$ \\
& $(78.4-113.1)$ & $(82.7-117.2)$ \\
FEV $1 / \mathrm{FVC} \mathrm{\%}$ & $90.3 \pm 2.6$ & $80.6 \pm 1.3^{*}$ \\
& $(79.3-106.4)$ & $(73.7-93.3)$ \\
$\mathrm{Pa}_{\mathrm{a}} \mathrm{CO}_{2} \mathrm{mmHg}$ & $40.8 \pm 0.5$ & $43.6 \pm 0.7^{*}$ \\
& $(36.2-42.2)$ & $(39.8-50.6)$ \\
$\mathrm{Pa}_{\mathrm{a}} \mathrm{O}_{2} \mathrm{mmHg}$ & $91.2 \pm 1.2$ & $83.8 \pm 2.4^{*}$ \\
& $(84.8-98.8)$ & $(66.9-95.6)$ \\
\hline
\end{tabular}

Values are means \pm SEM with ranges shown in parentheses. OSAS: obstructive sleep apnoea syndrome; M: male; F: female; BMI: body mass index; VC: vital capacity; FEV1/FVC: forced expiratory volume in one second/forced vital capacity; $P \mathrm{a}_{1} \mathrm{CO}_{2}$ : arterial carbon dioxide tension; $P \mathrm{a}, \mathrm{O}_{2}$ : arterial oxygen tension. *: $\mathrm{p}<0.05$. $(1 \mathrm{mmHg}=0.133 \mathrm{kPa}$. $)$

night polysomnography $[1,14]$. The patients with OSAS fulfilled the criteria for OSAS proposed by GUILLEMINAULT et al. [1]. All of the patients with OSAS snored and 
had excessive daytime sleepiness. The clinical characteristics of the patients with OSAS are shown in table 2. At the time of the study, no patient with OSAS had any evidence of hypothyroidism or heart failure. Five patients with OSAS had hypertension treated with calcium channel blockers or angiotensin-converting enzyme inhibitors. All medications were withdrawn under careful observation 1 week before the studies. No patient required administration of these medications during the study period. The control subjects were recruited from among hospital staff members who were naive concerning respiratory physiology. No control subjects had health problems and none were receiving any medication. Sleep-disordered breathing in the control subjects was screened for using a questionnaire and overnight measurement of arterial oxygen saturation $\left(\mathrm{Sa}_{\mathrm{a}} \mathrm{O}_{2}\right)$ with a pulse oximeter (Pulsox 7; Minolta, Osaka, Japan). Oral informed consent was obtained from each subject before the study. The study protocol was approved by the Institutional Review Board of Asahikawa Medical College. All subjects were instructed to refrain from drinking caffeine-containing beverages on the day of the study.

\section{Respiratory drives}

The effects on respiratory drive of chemical stimuli were assessed by the ventilatory response and mouth occlusion pressure response. All subjects fasted and were in a stable resting state for at least $30 \mathrm{~min}$ before the tests. They were seated in a comfortable chair, breathed through a lowresistance valve (Model 2700; Hans Rudolph, St Louis, MO, USA) and wore a rubber mouthpiece, noseclips and headphones, which supplied music devoid of strong rhythmic content. Inspiratory airflow was monitored by a Fleish-type pneumotachograph (MFP-1T-S; Nihon Koden, Tokyo, Japan) connected to the inspiratory site of the valve. Inspiratory tidal volume was derived by integration of the flow signal. During each test, inspiratory minute ventilation $\left(V^{\prime} \mathrm{I}\right)$ at body temperature, ambient pressure and water saturation (BTPS) conditions, tidal volume and

Table 2. - Patients with obstructive sleep apnoea syndrome

\begin{tabular}{lccc}
\hline $\begin{array}{l}\text { Patient } \\
\text { No. }\end{array}$ & $\begin{array}{c}\text { AI } \\
\mathrm{h}^{-1}\end{array}$ & $\begin{array}{c}\text { DSR4 } \% \\
\%\end{array}$ & $\begin{array}{c}\text { DSR10\% } \\
\%\end{array}$ \\
\hline 1 & 18.7 & 4.0 & 0.5 \\
2 & 56.3 & 20.2 & 5.8 \\
3 & 13.9 & 7.7 & 0.8 \\
4 & 20.3 & 22.0 & 7.2 \\
5 & 10.2 & 25.6 & 4.5 \\
6 & 47.5 & 56.2 & 28.5 \\
7 & 48.0 & 18.2 & 2.2 \\
8 & 18.7 & 4.0 & 1.0 \\
9 & 51.4 & 72.1 & 13.7 \\
10 & 45.5 & 52.2 & 16.3 \\
11 & 38.5 & 43.0 & 21.0 \\
12 & 26.2 & 13.1 & 1.2 \\
13 & 43.0 & 15.3 & 4.1 \\
14 & 21.4 & 63.1 & 4.9 \\
15 & 40.1 & 16.5 & 8.7 \\
16 & 60.0 & 19.0 & 11.0 \\
Mean \pm SEM & $35.0 \pm 8.7$ & $28.3 \pm 7.1$ & $8.2 \pm 2.1$ \\
\hline AI: & & &
\end{tabular}

AI: apnoea index; DSR4\%: 4\% desaturation ratio; DSR10\%: 10\% desaturation ratio. breathing frequency were measured continuously. On the inspiratory valve, an electromagnetic shutter was inserted to measure mouth occlusion pressure $\left(P_{0.1}\right)$, which is the pressure generated $0.1 \mathrm{~s}$ after occlusion by the inspiratory muscles at functional residual capacity. Measurement of $P 0.1$ was performed randomly every $5-10$ breaths during the hypercapnia and hypoxia tests as follows. Respiratory gas was sampled continuously from the mouthpiece formeasurements of breath-by-breath end-tidal carbon dioxide tension $\left(P\right.$ ET, $\left.\mathrm{CO}_{2}\right)$ and end-tidal oxygen tension $\left(P\right.$ ET, $\left.\mathrm{O}_{2}\right)$ using a mass spectrograph (Med Spect II; Chemetron, USA). $\mathrm{Sa}, \mathrm{O}_{2}$ was measured using the pulse oximeter. The electrocardiogram was monitored to determine cardiac frequency and detect incidental arrhythmias due to hypoxia.

The respiratory response to hypercapnia was measured using the rebreathing method [15]. In brief, a $6-\mathrm{L}$ bag, which was filled with gas composed of $5 \% \mathrm{CO}_{2}, 50 \% \mathrm{O}_{2}$ and $45 \% \mathrm{~N}_{2}$, was connected to the breathing valve and the subject rebreathed into the bag until $P \mathrm{ET}, \mathrm{CO}_{2}$ was $>9.3 \mathrm{kPa}$ $\left(70 \mathrm{mmHg}\right.$ ). During the tests, the $P \mathrm{ET}, \mathrm{O}_{2}$ was maintained $>13.3 \mathrm{kPa}(100 \mathrm{mmHg})$. One rebreathing test was usually terminated within $5 \mathrm{~min}$. The respiratory response to hypoxia was measured by the isocapnic progressive hypoxia method [16]. In brief, $P$ ET, $\mathrm{O}_{2}$ was lowered from 16.0 to 6.0 $\mathrm{kPa}$ (120 to $45 \mathrm{mmHg}$ ) over $7 \mathrm{~min}$ by the addition of $\mathrm{N}_{2}$. $\mathrm{CO}_{2}$ was added in amounts sufficient to maintain isocapnia. The respiratory drive was assessed by the slopes of $V^{\prime} \mathrm{I}$ and $P_{0.1}$ as functions of $P \mathrm{ET}, \mathrm{CO}_{2}$ and $\mathrm{Sa}_{\mathrm{a}} \mathrm{O}_{2}$.

\section{Hypoxic withdrawal responses}

The hypoxic withdrawal test [6-8] was used to evaluate the contribution of peripheral chemoreceptors to the ventilatory response. At the beginning of the test, $V^{\prime}$ I and $P$ ET, $\mathrm{CO}_{2}$ were measured while the subject was breathing room air in a rubber bag. $\mathrm{N}_{2}$ and $\mathrm{CO}_{2}$ were then added to room air in the rubber bag. The $P$ ET, $\mathrm{O}_{2}$ was gradually lowered to $8.0 \mathrm{kPa}(60 \mathrm{mmHg})$. At the same time, the $P$ ET, $\mathrm{CO}_{2}$ was elevated to $0.7 \mathrm{kPa}(5 \mathrm{mmHg})$ above the $P$ ET, $\mathrm{CO}_{2}$ during breathing of room air in order to stabilize ventilation. In this mildly hypercapnic hypoxic state, the hypoxic inspiratory gas was changed to $100 \% \mathrm{O}_{2}$ during two breaths without indicating this to the subject. After two breaths of $100 \% \mathrm{O}_{2}$, the inspiratory gas was switched back to the hypercapnic hypoxic gas. The $V^{\prime}$ I during room air breathing was defined as $V^{\prime} \mathrm{I}, \mathrm{N}$. The $V^{\prime}$ I before breathing $100 \% \mathrm{O}_{2}$ during the mildly hypercapnic hypoxic state was defined as $V^{\prime} \mathrm{I}, 0$. The $V^{\prime}$ I between 5 and $20 \mathrm{~s}$ after changing the inspiratory gas was defined as $V^{\prime} \mathrm{I}, 5-20$. The difference between $V^{\prime} \mathrm{I}, 0$ and $V^{\prime} \mathrm{I}, 5-20$ was defined as the withdrawal response $\left(\Delta V^{\prime} \mathrm{I}\right)$ and $\% \Delta V^{\prime} \mathrm{I}\left(\Delta V^{\prime} \mathrm{I} / V^{\prime} \mathrm{I}, 0 \times 100\right)$ was used as an index of the peripheral chemoreceptor activity (fig. 1 ). One exposure to hypoxia in this test was usually terminated within $7 \mathrm{~min}$. This withdrawal test was performed three or more times at intervals of $20 \mathrm{~min}$. The subject breathed room air between tests, to avoid the effects of hypoxic ventilatory depression.

\section{Drugs and protocol}

A double-blind study was performed to compare domperidone (Kyowa-Hakkou, Tokyo, Japan) with placebo on separate test days in a random order. The dose of domperidone was $0.5 \mathrm{mg} \cdot \mathrm{kg}^{-1}$ per os. The medicines were prepared 


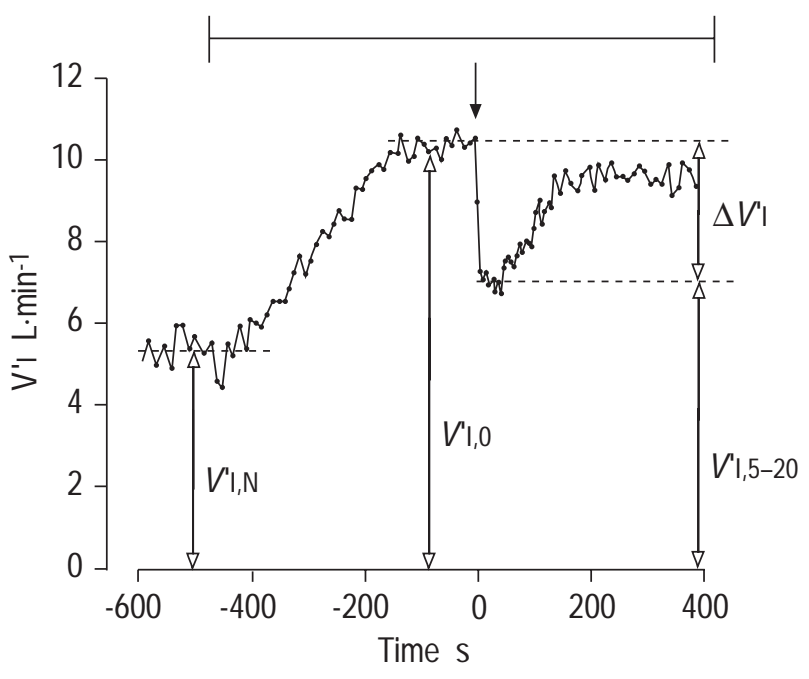

Fig. 1. - Representative recording of hypoxic withdrawal test results for a normal subject. Inspiratory minute ventilation $\left(V^{\prime} \mathrm{I}\right)$ was plotted against time (s). Initially, the subject breathed room air, and $V^{\prime} \mathrm{I}\left(V^{\prime} \mathrm{I}, \mathrm{N}\right)$ and endtidal carbon dioxide tension $\left(P \mathrm{ET}, \mathrm{CO}_{2}\right)$ were measured. Then, the endtidal oxygen tension $\left(P \mathrm{ET}_{2} \mathrm{O}_{2}\right)$ was gradually lowered to $8.0 \mathrm{kPa}(60$ $\mathrm{mmHg}$ ) and at the same time the $P$ ET, $\mathrm{CO}_{2}$ was elevated to $0.7 \mathrm{kPa}(5$ $\mathrm{mmHg}$ ) above the level of air ventilation (solid horizontal line). In this hypoxic state, the hypoxic inspiratory gas was changed to $100 \% \mathrm{O}_{2}$ during two breaths (filled vertical arrow). The ventilation after these two breaths of $\mathrm{O}_{2}$ was observed for about $120-180 \mathrm{~s}$. The $V^{\prime}$ I before breathing of $100 \% \mathrm{O}_{2}$ was defined as $V^{\prime} \mathrm{I}, 0$, and $V^{\prime}$ I between 5 and $20 \mathrm{~s}$ after changing the inspiratory gas was defined as $V^{\prime} \mathrm{I}, 5-20$. The difference between $V^{\prime} \mathrm{I}, 0$ and $V^{\prime} \mathrm{I}, 5-20$ was defined as the withdrawal response $\left(\Delta V^{\prime} \mathrm{I}\right)$ and $\% \Delta V^{\prime} \mathrm{I}\left(\Delta V^{\prime} \mathrm{I} / V^{\prime} \mathrm{I}, 0 \times 100\right)$ was used as an index of peripheral chemoreceptor activity.

by a controller and the investigators were blind to them until the end of the protocol for each patient. Drugs were administered to subjects $30 \mathrm{~min}$ before each test.

\section{Data analysis}

In the sleep study, apnoea was defined as cessation of flow at the nose and mouth for at least $10 \mathrm{~s}$. An apnoea index (total number of apnoeic episodes divided by the total sleep time in hours) was defined and computed as described by Guilleminault et al. [1]. Baseline $\mathrm{Sa}_{\mathrm{a}} \mathrm{O}_{2}$ was determined with the awake subject in a supine position. The periods with desaturations of $>4$ or $10 \%$ compared with the baseline $S \mathrm{a}_{1} \mathrm{O}_{2}$ were calculated; then the durations of desaturation as percentages of total sleep time were calculated as the $4 \%$ desaturation ratio (DSR $4 \%$ ) and $10 \%$ desaturation ratio (DSR10\%), respectively. The slopes of the $V^{\prime}$ I and $P_{0.1}$ responses to hypercapnia and hypoxia were calculated by least-squares regression analysis with $P$ ET, $\mathrm{CO}_{2}$ and $\mathrm{Sa}_{2} \mathrm{O}_{2}$, respectively. To eliminate the effects of body size and sex, the indices of each ventilatory response were corrected by body surface area (BSA) in square metres [17].

Values reported in the text and tables are means \pm SEM. Differences were tested for significance with the Wilcoxon test for intragroup comparison and the Mann-Whitney Utest was used for two independent groups. Correlations were assessed by calculating Spearman correlations coefficients. A p-value $<0.05$ was considered to indicate statistical significance.

\section{Results}

The characteristics of the two groups are shown in table 1. There was no significant difference in anthropometric values between patients with OSAS and control subjects. The mean values of forced expiratory volume in one second (FEV1)/forced vital capacity (FVC) and arterial oxygen tension $\left(\mathrm{Pa}_{\mathrm{a}} \mathrm{O}_{2}\right)$, although within the generally accepted normal range [18], were lower in patients with OSAS. The mean value of arterial carbon dioxide tension $\left(\mathrm{Pa}_{\mathrm{a}} \mathrm{CO}_{2}\right)$ was higher in the group of patients with OSAS, since this group included five patients with chronic hypoventilation $\left(\mathrm{Pa}_{\mathrm{a}} \mathrm{CO}_{2}\right.$ $\leq 6.0 \mathrm{kPa}(45 \mathrm{mmHg}))$.

The ventilatory responses to hypercapnia and hypoxia are shown in table 3. The mean values of the hypercapnic ventilatory response in the patient group was lower than that in the control group. Domperidone increased the respiratory drive to hypercapnia only in the patients with OSAS. In the patients with OSAS, each parameter of respiratory drive to hypoxia was significantly lower than that in the corresponding value in the control group. Domperidone did not alter the respiratory drive to hypoxia in either group.

There was no significant difference in $V^{\prime} \mathrm{I}, \mathrm{N}$ between the two groups (table 4). The $V^{\prime} \mathrm{I}, 0 / \mathrm{BSA}, \Delta V^{\prime} \mathrm{I} / \mathrm{BSA}$ and $\% \Delta V^{\prime} \mathrm{I}$ for patients with OSAS were lower than those for the control subjects. Domperidone increased $V^{\prime} \mathrm{I}, \mathrm{N}$ in neither the patients with OSAS nor the control subjects. Domperidone increased the $\Delta V^{\prime} \mathrm{I} / \mathrm{BSA}$ and $\% \Delta V^{\prime} \mathrm{I}$ in patients with OSAS, but not in control subjects. No difference was found in $\Delta V^{\prime} \mathrm{I} / \mathrm{BSA}$ or $\% \Delta V^{\prime} \mathrm{I}$ during administration of domperidone between the two groups. On subgroup analysis, no differences were observed in ventilatory responses to chemical stimuli or peripheral chemoreception between the OSAS patients without chronic hypercapnia and those with chronic hypercapnia (data not shown).

Correlations between ventilatory drive parameters and the results of polysomnography for the patients with OSAS are given in table 5. There was no significant correlation between the respiratory drive to hypercapnia and any of the indices of disturbance of ventilation during sleep. Hypoxic ventilatory response exhibited a negative correlation with DSR4\% (fig. 2). There were significant correlations between DSR $4 \%$ and $\% \Delta V^{\prime} \mathrm{I}$, and between DSR $10 \%$ and $\% \Delta V^{\prime}$ I. The apnoea index was correlated with neither hypoxic ventilatory response nor hypercapnic ventilatory response. Scatter plots of significant correlations in table 5 are illustrated in figure 2. Values for the OSAS patients with hypercapnia are indicated as open circles and they appeared to superimpose on each relationship. These findings showed that subgroup analysis was unlikely to alter the comprehensive findings of this study.

\section{Discussion}

The present study showed that: 1) respiratory drive to chemical stimuli was attenuated in patients with OSAS; 2 ) peripheral chemosensitivity was reduced in patients with OSAS; 3 ) domperidone increased the hypercapnic ventilatory response and the hypoxic withdrawal response in patients with OSAS; and 4) the hypoxic ventilatory response and hypoxic withdrawal response during wakefulness were negatively correlated with the severity of desaturation during sleep in patients with OSAS. 
Table 3. - Ventilatory responses to hypercapnia and hypoxia

\begin{tabular}{|c|c|c|c|c|}
\hline & \multicolumn{2}{|c|}{ Control subjects } & \multicolumn{2}{|c|}{ Patients with OSAS } \\
\hline & Placebo & Domperidone & Placebo & Domperidone \\
\hline 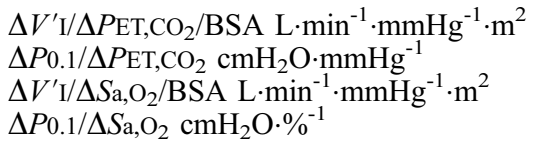 & $\begin{array}{l}0.96 \pm 0.09 \\
0.79 \pm 0.15 \\
0.55 \pm 0.08 \\
0.65 \pm 0.10\end{array}$ & $\begin{array}{l}0.85 \pm 0.16 \\
0.65 \pm 0.15 \\
0.62 \pm 0.11 \\
0.56 \pm 0.06\end{array}$ & $\begin{array}{l}0.71 \pm 0.10^{\dagger} \\
0.29 \pm 0.04^{\dagger} \\
0.34 \pm 0.06^{\dagger} \\
0.28 \pm 0.04^{\dagger}\end{array}$ & $\begin{array}{l}1.10 \pm 0.16^{*} \\
0.49 \pm 0.08^{*} \\
0.37 \pm 0.05 \\
0.22 \pm 0.05^{\dagger}\end{array}$ \\
\hline
\end{tabular}

Values are means \pm SEM. OSAS: obstructive sleep apnoea syndrome; $V^{\prime} \mathrm{I}$ : inspiratory minute ventilation; $P \mathrm{ET}_{2} \mathrm{CO}_{2}$ : end-tidal carbon dioxide tension; BSA: body surface area; $P_{0.1}$ : mouth occlusion pressure; $\Delta$ : difference; $S_{a}, \mathrm{O}_{2}$ : arterial oxygen saturation. (1 $\mathrm{mmHg}=0.133 \mathrm{kPa}$.) *: $\mathrm{p}<0.05$ placebo versus domperidone; ${ }^{\dagger}: \mathrm{p}<0.05$ control subjects versus patients with OSAS.

The nature of the ventilatory response to chemical stimuli in awake patients with OSAS is still unclear. Ventilatory drive in OSAS patients has been reported to be diminished $[19,20]$. In contrast, other investigators have concluded that ventilatory responses in OSAS patients are normal [21]. These discrepancies in findings concerning chemical ventilatory control in OSAS are due in part to differences in patient populations between these studies. Chronic hypercapnia is well recognized, though uncommon among OSAS patients during wakefulness [20, 22]. Hypercapnic OSAS patients have decreased respiratory drive compared with that in normocapnic OSAS patients $[19,20,22]$ and the chronic hypercapnia observed during wakefulness in patients with OSAS has been thought to reflect the impact of oxygen desaturation during sleep [23]. The findings obtained for ventilatory drive in patients with OSAS might be affected by the inclusion of hypercapnic OSAS patients in study populations. However, no differences were found in the chemical drives between the normocapnic patient group and the hypercapnic patient group in the present study. Previous studies have shown that tracheostomy and nasal continuous positive airway pressure enhanced ventilatory drive in OSAS patients with normocapnia and those with hypercapnia $[20,24]$. These findings suggest that the ventilatory drive in normocapnic patients with OSAS is probably depressed.

It has been demonstrated that ventilatory responses are negatively correlated with the degree of hypoxaemia during sleep in OSAS patients [4]. Hypercapnic OSAS patients have greater oxygen desaturation during sleep than those with eucapnic OSAS [5]. It is possible that frequent

Table 4. - Results of hypoxic withdrawal test

\begin{tabular}{cccccc}
\hline & \multicolumn{2}{c}{ Control subjects } & & \multicolumn{2}{c}{ Patients with OSAS } \\
\cline { 2 - 3 } \cline { 5 - 6 } & Placebo & $\begin{array}{c}\text { Domperi- } \\
\text { done }\end{array}$ & & Placebo & $\begin{array}{c}\text { Domperi- } \\
\text { done }\end{array}$ \\
\hline $\begin{array}{l}\Delta V^{\prime} \mathrm{I}, \mathrm{N} / \mathrm{BSA} \\
\mathrm{L} \cdot \mathrm{min}^{-1} \cdot \mathrm{m}^{-2}\end{array}$ & $5.4 \pm 0.2$ & $6.0 \pm 0.5$ & & $5.2 \pm 0.2$ & $5.0 \pm 0.0$ \\
$\begin{array}{c}\Delta V^{\prime} \mathrm{I}, 0 / \mathrm{BSA} \\
\mathrm{L} \cdot \mathrm{min}^{-1} \cdot \mathrm{m}^{-2}\end{array}$ & $10.2 \pm 1.1$ & $9.9 \pm 1.4$ & & $6.7 \pm 0.6^{\dagger}$ & $7.3 \pm 1.0$ \\
$\begin{array}{l}\Delta V^{\prime} \mathrm{I} / \mathrm{BSA} \\
\mathrm{L} \cdot \mathrm{min}^{-1} \cdot \mathrm{m}^{-2}\end{array}$ & $3.2 \pm 0.4$ & $3.0 \pm 0.4$ & & $1.3 \pm 0.2^{\dagger}$ & $2.4 \pm 0.2^{*}$ \\
$\% \Delta V^{\prime} \mathrm{I} \%$ & $31 \pm 3$ & $32 \pm 4$ & & $19 \pm 3^{\dagger}$ & $36 \pm 3^{*}$ \\
\hline
\end{tabular}

Values are means \pm SEM. OSAS: obstructive sleep apnoea syndrome; $V^{\prime} \mathrm{I}, \mathrm{N}$ : inspiratory minute ventilation during breathing of room air; BSA: body surface area; $V^{\prime} \mathrm{I}, 0$ : inspiratory minute ventilation during hypercapnic hypoxia; $V^{\prime}$ I,5-20: $V^{\prime}$ I between 5 and $20 \mathrm{~s}$ after changing the inspiratory gas; $\Delta V^{\prime} \mathrm{I}: V^{\prime} \mathrm{I}, 0-V^{\prime} \mathrm{I}, 5-20$; $\% V^{\prime} \mathrm{I}=V^{\prime} \mathrm{I} / V^{\prime} \mathrm{I}, 0 \times 100 . *: \mathrm{p}<0.05$ placebo versus domperidone; : $\mathrm{p}<0.05$ control subjects versus patients with OSAS. asphyxia during sleep causes adaptation and resetting of the ventilatory responses to chemical stimuli in OSAS patients.

Results of twin studies suggest that ventilatory drives are controlled by genetic factors [25]. Familial aggregation of blunt ventilatory responses to chemical stimuli have been demonstrated for healthy members of the families of OSAS patients [26]. The findings of the present study and previous studies suggest that both genetic and acquired factors contribute to the changes in ventilatory drives observed in patients with OSAS.

In order to determine peripheral chemoreceptor activity in awake humans, the hypoxic withdrawal test was used to exclude factors other than the peripheral chemoreceptor activity. The merits of withdrawal tests in the evaluation of peripheral chemoreception have been reported by MILLER et al. [27]. In the present study, the change in $V^{\prime}$ I during the 5-20-s period following the end of the first $\mathrm{O}_{2}$ inspiration was defined as the withdrawal response. Since the time required for circulation from the lung to the central nervous system is considered to be about $20 \mathrm{~s}$, the hypoxic withdrawal test eliminates peripheral chemoreceptor activity but leaves the humoral environment of the central respiratory regulating system unchanged. $\Delta V^{\prime}$ I and $\% \Delta V^{\prime}$ I are, therefore, due to the transient cessation of peripheral chemoreceptor activity.

A preliminary study by the authors estimated the spontaneous variation in five repeated tests of hypoxic withdrawal responses in single subjects. The mean of the coefficient of variance of $\Delta V^{\prime}$ I was $12.8 \%$ (range $8.8-$ $15.6 \%$ ) in six healthy subjects. This value was equal to indices of ventilatory responses given in previous reports.

Table 5. - Coefficients of correlation between apnoea index (Al), oxygen desaturation ratios and ventilatory responses in patients with obstructive sleep apnoea syndrome

\begin{tabular}{|c|c|c|c|}
\hline & AI & DSR4\% & DSR $10 \%$ \\
\hline \multicolumn{4}{|l|}{ Hypercapnic response } \\
\hline$\Delta V^{\prime} \mathrm{I} / \Delta P \mathrm{ET}, \mathrm{CO}_{2} / \mathrm{BSA}$ & -0.073 & -0.116 & -0.041 \\
\hline$\Delta P 0.1 / \Delta P \mathrm{ET}, \mathrm{CO}_{2}$ & 0.31 & -0.048 & 0.088 \\
\hline Hypoxic response & & & \\
\hline$\Delta V^{\prime} \mathrm{I} / \Delta \mathrm{Sa}_{\mathrm{a}, \mathrm{O}_{2}} / \mathrm{BSA}$ & -0.378 & $-0.687 *$ & -0.577 \\
\hline$\Delta P 0.1 / \Delta S_{\mathrm{a}, \mathrm{O}_{2}}$ & -0.112 & -0.447 & -0.416 \\
\hline $\begin{array}{l}\text { Hypoxic withdrawal res } \\
\% \Delta V^{\prime} \mathrm{I}\end{array}$ & -0.141 & $-0.654 *$ & $-0.644 *$ \\
\hline
\end{tabular}

DSR4\%: 4\% desaturation ratio; DSR10\%: $10 \%$ desaturation ratio; $\Delta$ : difference; $V^{\prime} \mathrm{I}$ : inspiratory minute ventilation; $P \mathrm{ET}, \mathrm{CO}_{2}$ : end-tidal carbon dioxide tension; BSA: body surface area; $P_{0.1}$ : mouth occlusion pressure; $\mathrm{Sa}_{\mathrm{a}} \mathrm{O}_{2}$ : arterial oxygen saturation. *: $\mathrm{p}<0.05$. 

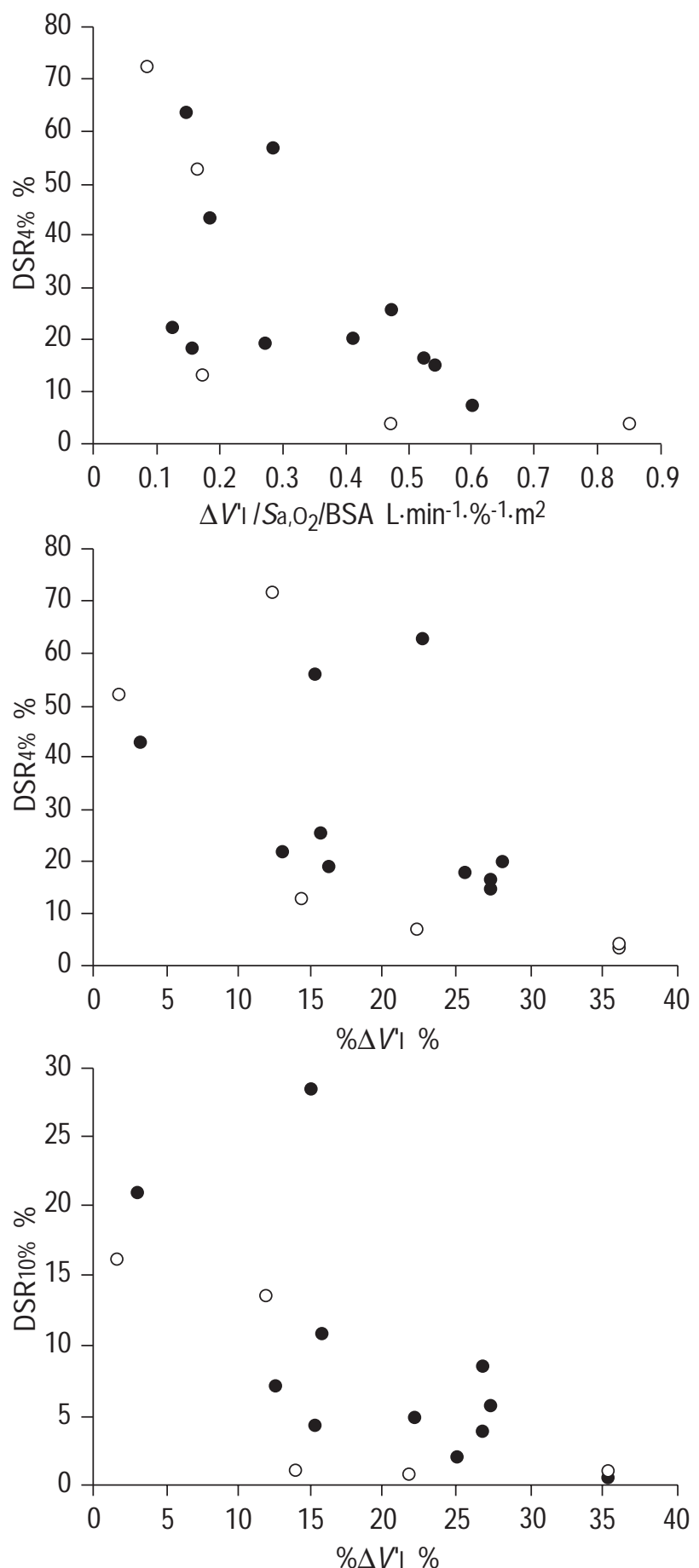

Fig. 2. - Scatter plots of significant correlations between oxygen desaturation ratio during sleep and ventilatory response in obstructive sleep apnoea syndrome with normocapnia (•) and those with chronic hypercapnia (O). DSR4\%: 4\% desaturation ratio; DSR $10 \%$ : $10 \%$ desaturation ratio; $\Delta$ : difference; $\left.V\right|^{\prime}$ I: inspiratory minute ventilation; $\mathrm{Sa}_{\mathrm{a}} \mathrm{O}_{2}$ : arterial oxygen saturation; BSA: body surface area.

The magnitude of change in responses to treatment with domperidone appeared to be significant, compared with spontaneous variation in the indices of ventilatory responses observed in the present study.

Dopamine is a major transmitter in the carotid body [9, 10]. In an animal study, exogenous dopamine reduced ven- tilatory responses to chemical stimuli owing to the inhibition of carotid chemoreception and dopamine antagonists augmented the ventilatory response [28]. Human studies have also shown that i.v. dopamine administration reduces the ventilatory responses to both hypoxia and hypercapnia $[12,29]$. Dopamine appears to be an inhibitory transmitter in the mammalian carotid body.

Domperidone is a selective dopaminergic receptor antagonist $\left(\mathrm{D}_{2}\right)$ and only minimally crosses the blood-brain barrier [13]. It has been shown that, unlike other such antagonists, domperidone has no $\alpha_{2}$-adrenoreceptor-blocking activity [30]. Therefore, domperidone was used to examine the roles played by endogenous dopamine in peripheral chemoreceptors.

It has been demonstrated in animal studies that the hypercapnic ventilatory response [31] and carotid chemosensory discharge response to hypercapnia [32] are enhanced by domperidone. The hypercapnic ventilatory response was not enhanced by domperidone in carotid body-denervated animals [31]. These findings appear to support the hypothesis that domperidone potentiates hypercapnic ventilatory responses in humans via the effects on peripheral chemosensitivity. The findings of the present study appear to be compatible with those of the animal studies noted above.

DelPIERRE et al. [33] reported that i.v. administration of domperidone increased hypoxic ventilatory response in healthy subjects. In the present study, domperidone changed neither the ventilatory responses to chemical stimuli nor peripheral chemosensitivity in control subjects. This discrepancy in findings between the previous studies and the present investigation might be explained by differences in serum concentrations of domperidone. A safe dose of orally administered domperidone was used in the present study to avoid serious cardiac side-effects [34]. This dose of domperidone has been demonstrated clearly to modulate the effects of dopamine in the gastrointestinal tract [35]. However, the same dose of domperidone increased peripheral chemosensitivity in the patients with obstructive sleep apnoea syndrome in the present study. One interpretation of these findings is that patients with obstructive sleep apnoea syndrome have an abnormality of dopaminergic mechanisms in peripheral chemoreceptors. More specifically, the effects of dopamine on the peripheral chemoreceptors of patients with obstructive sleep apnoea syndrome might be increased and in such patients these receptors might be more sensitive to dopamine receptor antagonists than are those of healthy subjects. However, this hypothesis requires more systematic pharmacological study for testing and direct evidence of abnormality of dopaminergic mechanisms in patients with obstructive sleep apnoea syndrome.

\section{References}

1. Guilleminault C, Tilkian A, Dement WC. The sleep apnea syndrome. Annu Rev Med 1976; 27: 465-484.

2. Hudgel DW. Mechanisms of obstructive sleep apnea. Chest 1992; 101: 541-549.

3. Önal E, Lopata L. Periodic breathing and the pathogenesis of occlusive sleep apneas. Am Rev Respir Dis 1982; 126: 676-680.

4. Kunitomo F, Kimura H, Tatsumi K, et al. Abnormal breathing during sleep and chemical control of breathing 
during wakefulness in patients with sleep apnea syndrome. Am Rev Respir Dis 1989; 139: 164-169.

5. Satoh M, Hida W, Chonan T, et al. Role of hypoxic drive in regulation of postapneic ventilation during sleep in patients with obstructive sleep apnea. Am Rev Respir Dis 1991; 143: 481-485.

6. Dejours P. Control of respiratory by arterial chemoreceptors. Ann NY Acad Sci 1963; 109: 682-695.

7. Honda $\mathrm{Y}$, Watanabe S, Hashizume I, et al. Hypoxic chemosensitivity in asthmatic patients two decades after carotid body resection. J Appl Physiol 1979; 46: 632-638.

8. Matsumoto H, Osanai S, Akiba Y. Effect of dopamine and haloperidol on ventilatory responses in man. Jpn J Appl Physiol 1992; 22: 419-429.

9. Zapata P, Hess A, Bliss EL, Eyzaguirre C. Chemical, electron microscopic and physiological observation on the role of catecholamines in the carotid body. Brain Res 1969; 14: 473-498.

10. Fidone SJ, Gonzalez C, Obeso A, Gomez-Nino A, Dinger B. Biogenic amine and neuropeptide transmitters in carotid body chemoreception: experimental findings and perspectives. In: Sutton JR, Coates G, Remmers JE, eds. Hypoxia: the Adaptations. New York, Marcel Decker, 1990; pp. 116-126.

11. Llados F, Zapata P. Effects of dopamine analogs and antagonists in carotid body chemosensors in situ. J Physiol (Lond) 1978; 274: 478-499.

12. Lahiri S, Nishino T, Mokashi A, Mulligan E. Interaction of dopamine and haloperidol with $\mathrm{O}_{2}$ and $\mathrm{CO}_{2}$ chemoreception in the carotid body. $J$ Appl Physiol 1980; 49: $45-51$.

13. Laduron PM, Leysen JE. Domperidone, a specific in vitro dopamine antagonist, devoid of in vitro central dopaminergic activity. Biochem Pharmacol 1979; 28: 2161-2165.

14. Stradling JR. Handbook of Sleep-related Breathing Disorders. Oxford, Oxford University Press, 1993.

15. Read DJC. A clinical method for assessing the ventilatory response to carbon dioxide. Austr Ann Med 1975; 16: 20 32.

16. Weil JV, Byrne-Quinn E, Sodal IE, et al. Hypoxic ventilatory drive in normal man. J Clin Invest 1970; 49: 1061-1072.

17. Aitken ML, Franklin JL, Pierson DJ, Schoene RB. Influence of body size and gender on control of ventilation. J Appl Physiol 1986; 60: 1894-1899.

18. American Thoracic Society. Lung function testing: selection of reference values and interpretative strategies. $\mathrm{Am}$ Rev Respir Dis 1991; 144: 1202-1218.

19. Lopata M, Önal E. Mass loading, sleep apnea, and the pathogenesis of obesity hypoventilation. Am Rev Respir Dis 1982; 126: 640-645.

20. Lin CC. Effect of nasal CPAP on ventilatory drive in normocapnic and hypercapnic patients with obstructive sleep apnoea syndrome. Eur Respir J 1994; 7: 2005-2010.

21. Benlloch E, Cordero P, Morales P, Soler JJ, Macián V.
Ventilatory pattern at rest and response to hypercapnic stimulation in patients with obstructive sleep apnea syndrome. Respiration 1995; 62: 4-9.

22. Garay SM, Rapaport D, Sorkin B, Epsein H, Feinberg I, Goldring RM. Regulation of ventilation in the obstructive sleep apnea syndrome. Am Rev Respir Dis 1981; 124: 451-457.

23. Jones BJ, Wilhoit SC, Findley LJ, Suratt PM. Oxyhemoglobin saturation during sleep in subjects with and without the obesity hypoventilation syndrome. Chest 1985; 88: 9-15.

24. Guilleminault C, Cummiskey J. Progressive improvement of apnea index and ventilatory response to $\mathrm{CO}_{2}$ after tracheostomy in obstructive sleep apnea syndrome. $\mathrm{Am}$ Rev Respir Dis 1982; 126: 14-20.

25. Collins DD, Scoggin CH, Zwillich CW, Weil JV. Hereditary aspects of decreased hypoxic response. J Clin Invest 1978; 70: 105-110.

26. Bayadi SF, Millman RP, Tishler PV, et al. A family study of sleep apnea: anatomic and physiologic interaction. Chest 1990; 98: 554-559.

27. Miller JP, Cunningham DJC, Lloyd BB, Young JM. The transient respiratory effects in man of sudden changes in alveolar $\mathrm{CO}_{2}$ in hypoxia and in high oxygen. Respir Physiol 1974; 20: 17-31.

28. Bisgard GE, Forster HV, Klein JP, Manohar M, Bullard VA. Depression of ventilation by dopamine in goats effects of carotid body excision. Respir Physiol 1980; 41: 379-392.

29. Olson LG, Hensley MJ, Saunders NA. Ventilatory responsiveness to hypercapnic hypoxia during dopamine infusion in human. Am Rev Respir Dis 1982; 126: 783787.

30. Kohli JD, Glock D, Goldberg LI. Selective $\mathrm{DA}_{2}$ versus $\mathrm{DA}_{1}$ antagonist activity of domperidone in the periphery. Eur J Pharm 1983; 89: 137-141.

31. Kressin NA, Nielsen AM, Laravuso R, Bisgard GE. Domperidone-induced potentiation of ventilatory responses in awake goats. Respir Physiol 1986; 65: 169-180.

32. Hsiao C, Lahiri S, Mokashi A. Peripheral and central dopamine receptors in respiratory control. Respir Physiol 1989; 76: 327-336.

33. Delpierre S, Fornaris M, Guillot C, Grimaud C. Increased ventilatory chemosensitivity induced by domperidone, a dopamine antagonist, in healthy humans. Bull Eur Physiopathol Respir 1987; 23: 31-35.

34. Osbone RJ, Slevin ML, Hunter RW, Hamer J. Cardiac arrhythmias during cytotoxic chemotherapy: role of domperidone. Hum Toxicol 1985; 4: 617-626.

35. Brogden RN, Carmine AA, Heel RC. Domperidone: a review of its pharmacologic activity, pharmacokinetics and therapeutic efficacy in the symptomatic treatment of chronic dyspepsia and as anti-emetic. Drugs 1982; 24: $360-400$. 